\title{
A ARTE TRANSFORMADA EM PALAVRAS
}

\author{
Edina Regina Pugas Panichi \\ Universidade Estadual de Londrina (Brasil) \\ edinapanichi@sercomtel.com.br
}

Recebido: 29/05/2020 - Aprovado: 06/07/2020 - Publicado: 15/04/2021

DOI: doi.org/10.17533/udea.lyl.n79a27

Resumo: Este artigo analisa a construção textual do Pedro Nava, com base na crítica genética e estilística. Serão analisados os documentos de processo utilizados e os princípios que direcionam a busca pela composição estética. A mistura de elementos artísticos e literários na formulação da escrita do autor, bem como a utilização de desenhos na construção dos personagens, resultam na concretização de um pensamento marcadamente visual, uma vez que a condensação da visualidade passa por um processo de expansão na transformação de imagens em palavras, resultando num estilo raro do ponto de vista plástico e imagético.

Palavras-chave: Pedro Nava; arte; literatura; estilística; crítica genética.

\section{ART TRANSFORMED INTO WORDS}

Abstract: This article analyzes the textual construction of Pedro Nava, based on the genetic and stylistic criticism. The documents of processes used and the principles that guide the search for aesthetic composition will be analyzed. The mixture of artistic and literary elements in the formulation of the author's writing, as well as the use of drawings in the construction of the characters, result in the realization of a markedly visual thought, since the condensation of visuality goes through an expansion process in transformation of images into words, resulting in a rare style from a plastic and imagetic point of view. Key words: Pedro Nava; art; literature; stylistic; genetic criticism. 


\section{Introdução}

M

uito se tem discutido a respeito da exuberância da linguagem, a versatilidade semântica e o pendor literário de Pedro Nava, considerado um dos maiores memorialistas brasileiros. Pedro da Silva Nava (1903-1984) nasceu em Juiz de Fora, Minas Gerais, e foi um médico, poeta e memorialista brasileiro. Sua obra autobiográfica captou o espírito de sua época e traçou um painel da cultura brasileira no século Xx. Em 1972 publicou o primeiro livro, Baú de Ossos, seguido de Balão Cativo (1973), Chão de Ferro (1976), Beira-Mar (1978), Galo-das-Trevas (1981) e O Círio Perfeito (1983). O sétimo volume, Cera das Almas, ficou incompleto e foi publicado, postumamente, em 2004. Pedro Nava, até então, era conhecido como poeta bissexto e foi incluído por Manuel Bandeira na sua Antologia de Poetas Brasileiros Bissextos Contemporâneos (1946, pp. 169-183) com sete produções, dentre as quais encontra-se «O Defunto», seu poema mais conhecido e elogiado. Pedro Nava formou-se em Medicina na Universidade Federal de Minas Gerais e participou da geração modernista de Belo Horizonte juntamente com Carlos Drummond de Andrade, Emílio Moura, Abgar Renault, entre outros.

A despeito da surpresa provocada quando da publicação de Baú de Ossos, o nome e a presença de Pedro Nava vinham de longe, dos anos 1920. Muito cedo, ainda estudante, o futuro memorialista já se distinguira na sua geração. Em abril de 1924, Nava teve o privilégio de encontrar Mário de Andrade, em sua primeira viagem a Minas, integrando a famosa Caravana Paulista, composta por Dona Olívia Guedes Penteado, Tarsila do Amaral, o poeta francês Blaise Cendrars, Oswaldo de Andrade, Gofredo Telles, Noné (Oswald de Andrade Filho) e o próprio Mário (Nava, 1979). Dessa forma, um jovem escritor que ensaiava os primeiros passos e um crítico já consciente do que queria e que gostava de dizê-lo, estabelecem uma correspondência que durou vinte anos. Numa das cartas a Pedro Nava, datada de 10 de abril, 1927, Mário de Andrade (1982, p. 90) se refere à «suntuosidade artística» do então jovem poeta com quem se correspondia, já lhe reconhecendo a escrita invejável. Ao empregar essa fórmula sintética, referindo-se aos versos do amigo, o escritor paulista punha em destaque justamente uma das características que haveria de constituir um dos traços marcantes da obra em prosa que, quase meio século depois, iria reservar ao escritor mineiro um lugar privilegiado em nossas letras.

Pedro Nava iniciou a sua carreira literária muito tarde. Começou a escrever Baú de Ossos em 1968 e o publicou

no limiar dos seus setenta anos. É quase inacreditável como o escritor, com a força de um estilo mágico, o seu raro poder de observação, a capacidade de fixar tipos e ambientes, de recompor personalidades e situações, de analisar fatos e almas, pôde, através de longa vida, sofrear o dom literário que o habitava e por certo tentava arrastá-lo para o terreno das letras. Os relatos evocativos do autor não raro assumem uma dimensão plástica, confundindose com traçados documentários capazes de fixar os aspectos fisionômicos, o estilo e o contorno dos corpos dos personagens, bem como suas características psicológicas num diálogo entre imagem e palavra, obedecendo a um acompanhamento linear no processo construtivo do texto. A plasticidade criativa de Nava se volta para os conhecimentos da arte e da literatura recompondo os seus personagens com a agilização artística e a moldura psicológica de uma escrita pictórica e caricatural. O próprio autor confessou esse processo de figurabilidade que o perseguiu: «Sempre tive a mania de descobrir semelhanças não só entre as pessoas, entre as pessoas com figuras 
da escultura e da pintura, como também entre personagens da vida real e os da ficção» (Nava, 1979, p. 201).

A crítica genética permite compreender que uma obra de arte, um texto ou qualquer fruto da criação humana passa por um processo de construção antes de chegar ao domínio público. Essa perspectiva amplia a compreensão da criação e revela o que o texto definitivo não consegue transmitir, ou seja, a obra em processo, os caminhos seguidos pelo autor, suas dúvidas e incertezas, decisões e escolhas. O processo criativo e a gênese do texto comprovam que o ato de escrever não está sujeito apenas à imaginação; ele é resultado de leituras, pesquisas, anotações e consultas que revelam os bastidores da criação e a importância da atenção dispendida na elaboração do processo construtivo da obra. A crítica genética teve início na França, em 1968, e seus primeiros estudos foram coordenados por Louis Hay, envolvendo os manuscritos do poeta alemão Heinrich Heine. No Brasil, a crítica genética chegou em 1985 através de Philippe Willemart, que organizou o I Colóquio de Crítica Textual: O Manuscrito Moderno e as Edições, na Universidade de São Paulo - USP. Nesse mesmo ano foi fundada a Associação dos Pesquisadores do Manuscrito Literário (APML). Com o passar do tempo, a APML passou a chamar-se APCG (Associação dos Pesquisadores em Crítica Genética), uma vez que os estudos genéticos ganharam novos contornos para além do manuscrito literário englobando as mídias, a dança, o cinema, o teatro e outras manifestações artísticas num novo campo transdisciplinar.

Tendo em vista a ampliação do número de pesquisadores e abordagens teóricas, «a crítica genética ampliou seu espaço, criando novos laços com outros campos do saber, deslocando o olhar do pesquisador do produto acabado para o processo» (Willemart, 2009, p. 58). O crítico genético trabalha a partir da análise dos documentos deixados pelos autores como anotações, esboços, desenhos, caricaturas, rascunhos, etc. Em seu trabalho de pesquisa passa a conviver com o ambiente do fazer artístico, sendo conduzido pelo universo de quem o produz a partir das marcas deixadas pelo criador, os movimentos de ir e vir de suas mãos. Quando se analisa o fazer artístico, acompanhase um pensamento em construção e a efetivação dos registros nem sempre é detectada na obra pronta: «O que o crítico genético observa são os índices visíveis de um trabalho; o que ele decifra não é o movimento de um espírito, mas o traço de um ato» (Hay, 2007, p. 19). Quando se está diante de um produto acabado não se tem a exata dimensão do que significou produzi-lo. Um arquivo preservado é um estoque de formas que que por si mesmas já são traduções preliminares da realidade. Em seu conjunto, essas formas traçam o mapa do raciocínio, seguido pelo autor e o entendimento do percurso criativo, suas idas e vindas, só acontece plenamente por meio da análise de tais documentos que permitem que os diversos componentes do ato criador, bem como suas relações, sejam deflagrados.

A estilística, por seu lado, é uma das disciplinas voltadas para os fenômenos da língua, tendo por objetivo «explicar os usos da linguagem que ultrapassam a função puramente denotativa» (Martins, 2012, p. 22). Assim, os estudos estilísticos não se limitam a demonstrar os valores denotativos de determinado idioma, mas também se prestam a desvendar os valores emotivos e psíquicos que despertam, no receptor, reações afetivas. São infinitas as possibilidades de se explorar os recursos de linguagem que podem ser utilizados para realçar ou destacar uma ideia, remeter a uma situação ou causar emoção, bem como para aflorar a formalidade, o encantamento, a 
afetividade ou a sensibilidade. O resultado estilístico depende da associação entre os recursos disponíveis, pois as palavras ganham sentido de acordo com a intenção com que são utilizadas. A estilística, portanto, oferece os meios para interpretar e utilizar os diferentes recursos que a língua oferece, ajudando a compreender certos fenômenos expressivos e tornando perceptíveis as variantes de estilo de cada classe social, de cada região ou cultura, bem como a intenção comunicativa daquele que fala.

O escritor, no processo interpretativo de sua visão da realidade para chegar a cristalizá-la em palavras, tem por força que realizar uma seleção qualitativa e quantitativa de seus meios de expressão. O processo de seleção e combinação permite-lhe então aproveitar o repertório que o código linguístico lhe faculta, aqueles signos mais ajustáveis à expressão de seu pensamento, pois «a obra literária não é senão comunicação e qualquer fator estilístico que o escritor nela faça entrar não é, definitivamente, mais que um meio de, com segurança, conseguir a adesão do leitor» (Cressot, 1980, p. 15). É manifesta a preocupação de Pedro Nava com a minúcia, revelando a necessidade de o autor buscar os pormenores foi evidenciar os diversos aspectos das pessoas e dos acontecimentos que perpassam por toda a sua obra. Outra dimensão fundamental da atitude estilística do autor e que revela a sua capacidade de evocação foi a exploração que faz do poder expressivo das palavras, ora evidenciando os efeitos oriundos de certas combinações sonoras, com novas relações entre o som e o significado e a sua correspondência no espírito, ora perscrutando as potências sugestivo-imitativas latentes nos próprios termos que selecionou para servir de apoio sensorial à ideia que pretendeu repassar ao leitor.

Para descrever os seus personagens, Pedro Nava lançou mão da simbiose arte-literatura associando cores, movimentos, sombras, luzes, emprestando ao texto dinâmica, expressão e perspectiva, que lhe possibilitam alcançar um melhor relevo visual. Essa mistura de elementos artísticos e literários na formulação da escrita levam o leitor a buscar as referências e a pesquisar os indicadores históricos para melhor se posicionar no universo literário do autor e assimilar a estética da forma e a significação da mensagem. Assim, é tarefa do geneticista «tornar disponível, acessível e legível os documentos autógrafos que não passam, num primeiro momento, de peças de arquivos, mas que ao mesmo tempo contribuíram para a elaboração de um texto e servem de testemunhas materiais de uma dinâmica criadora» (Grésillon, 2007, p. 29).

Os longos anos dedicados à medicina foram decisivos para o amadurecimento do estilo do autor. Formado em 1927, Nava passou a vida estudando e aperfeiçoando-se na profissão que abraçou. A influência da medicina é patente em sua escrita. Contudo, os melhores resultados da infiltração médica no discurso literário de Nava se dão quando o escritor superou o cientista, absorvendo o domínio da linguagem hipocrática na construção artística da obra. Como médico, Nava mantinha suas atividades de desenhista e pintor bissexto. Suas leituras sobre arte, somadas às visitas que empreendeu aos grandes museus da Europa e da América, possibilitaram-lhe adquirir, nesse campo, um saber equiparável ao que possuía no terreno da literatura.

As citações de artistas e telas, ao longo de sua escrita, chegam a impressionar. A transposição da experiência de Nava no campo das artes não se evidencia somente nas incontáveis citações de pintores e quadros em suas memórias. Ela se mostra também em passagens nas quais se sente a mão do desenhista apoiando a do escritor. 
$\mathrm{O}$ ato de lembrar adquire, em Pedro Nava, diversas formas. Esses diferentes modos de trazer à tona a lembrança mostram que Nava entendia bem o funcionamento da memória individual e utilizava conscientemente as possibilidades de manifestação da lembrança para causar um efeito literário. Daí obter o leitor, através de seu texto, a sensação de um estilo autobiográfico único, porque as diversas maneiras de a imagem se manifestar na memória foram exploradas pelo autor com um colorido e uma riqueza de detalhes que imprimem à escritura um forte teor artístico.

\section{A composição dos personagens através da arte}

Ao descrever os seus personagens, Nava não dispensou o arcabouço criativo, desenhando fisionomias, ampliando imagens e interpretando molduras na busca de efeitos comparativos para a elaboração da arte final. Uma de suas técnicas é fazer a mediação entre os personagens e pinturas e esculturas. Na passagem a seguir, o autor deixou claro o propósito da interposição, chamando a atenção para a tela Primavera, do pintor renascentista Sandro Botticelli, que retrata um grupo de figuras mitológicas, a maioria de perfil. Acrescentou às visões analógicas que os passeios pelas ruas de Belo Horizonte lhe proporcionavam, a imagem de Santa Cacilda de Toledo, do pintor Francisco de Zurbarán, valendo-se da pose captada pelo artista para retratá-la e vinculando a modelo à beldade debruçada no parapeito do terraço, visão alcançada pela prodigiosa memória do narrador:

Certas janelas pareciam quadros. Na casa do Dr. Bernardino o perfil da Auxiliadora fazia um Sandro Botticelli. Primavera. Santa Cacilda, de Zurbarán, debruçava-se no peitoril do terraço da família Tamm. Em cada esquina a Petrina ia satisfazendo as curiosidades de minha Mãe. Diante de Álvares Cabral eram as Teixeira morenas e logo apareciam as louras Amador, as louras Moss, a loura Gutierrez — bem chamada de Aurora (Nava, 1986, p. 148).

Há, aqui, uma forte influência das artes visuais, responsável pelas imagens geradas. As janelas se transformam em molduras metaforizadas e as obras de arte amparam as descrições que repetem os movimentos dos originais, o que implica uma tentativa de transmitir um efeito de movimento ao quadro descrito. $\mathrm{O}$ autor revelou uma grande capacidade de evocação. Apresenta os retratos admiráveis, valendo-se para isso de farta documentação, desenhos que ele mesmo fazia e reproduções que arquivava com o intuito de reavivar a lembrança de determinados personagens, como se pode perceber pelos recortes, gravuras e desenhos encontrados em seus arquivos e que se encontram sob a guarda do Arquivo Museu de Literatura Brasileira (AMLB), instalado na Fundação Casa de Rui Barbosa, no Rio de Janeiro. 


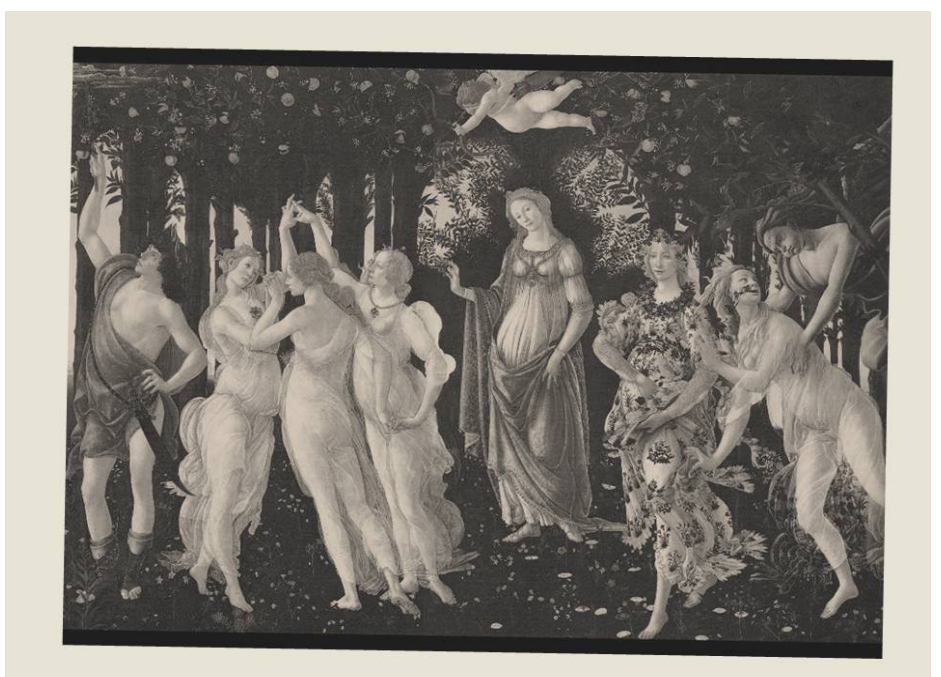

Figura 1. Reprodução do quadro Primavera, de Sandro Botticelli, arquivada por Pedro Nava. Fonte: AMLB.

A mesma pintura de Botticelli restitui ao autor uma paixão da juventude que lhe deixou tristes lembranças. A leucemia levou a noiva ao suicídio e o mito da ninfa Dafne, colocado no texto, parece vaticinar o trágico que estaria por vir:

O pequeno jardim, o pinheiro em cuja folhagem ela se encostava para sorrir de dentro do verde macio e ficar que nem alegoria mito de Dafne árvore mulher, como uma das figuras da direita da Primavera de Botticelli - a que morde um ramo ou a de roupas florais se franjando em galhos folhagens ramagens (Nava, 1979, p. 257).

Aqui o autor procurou extrair de sua matéria verbal tudo quanto essa lhe possa oferecer de plasticidade, ritmo, harmonia e efeito evocativo, pois a memória «nos permite guardar uma espécie de acervo de nossas ações e experiências» (Ostrower, 1999, p. 261). Ao comparar a amada com a imagem de roupas florais se franjando em galhos folhagens ramagens, Nava omitiu a pontuação para alcançar resultados estilísticos expressivos e rítmicos, pois a iteração das consoantes fricativas sugere o farfalhar das folhas. A supressão das vírgulas, elidindo as pausas entre os termos, resulta ainda em uma musicalidade evocativa que emana de sua integração no conjunto significativo da obra de arte eleita para a mediação entre a amada e a personagem de Botticelli. Assim, as linguagens visual e verbal se entrelaçam na tentativa de traduzir a trajetória poética do raciocínio do autor.

Nava reviveu e ressuscitou, com todas as cores, os inúmeros tipos que desfilaram por sua produção, pondo de pé as figuras que evoca. A crítica genética permite recuperar os rastros da criação desde os primeiros esboços até as correções finais feitas pelo autor. $O$ texto que chega ao leitor nada mais é que o último passo de um longo percurso que vai do projeto inicial ao resultado final. O crítico genético mostra os bastidores da criação, a intimidade do gesto criador, ou seja, o processo de fabricação do texto. Os documentos arquivados por Pedro Nava oferecem vários exemplos de utilização da linguagem visual em diálogo com a página escrita. Nava desenhava o que pretendia retratar ou arquivava recortes de inúmeras fontes e, a partir deste material, elaborava o seu texto. Assim, sua capacidade de reprodução quase fotográfica dos tipos e acontecimentos sustenta um estilo rico do ponto de 
vista plástico e imagético.

A representação da imagem em Pedro Nava, ou seja, os retratos elaborados pelo autor, foram baseados em desenhos, telas, gravuras ou fotografias. Ao descrever um personagem, o memorialista terá como ponto de partida um destes elementos. A sua grande curiosidade de inquiridor — legado da profissão —, levava-o a descer a minúcias como se desejasse fazer um diagnóstico, aplicando sua ciência à língua. A atenção aos detalhes foi aguçada pelos longos anos dedicados à medicina, como ele mesmo revelou: «Aprendi a olhar, a ver como médico. Temos que usar os nossos sentidos de maneira absoluta, tirar deles tudo o que possam render. Modéstia à parte, sei observar» (Nava, 1983, p. 54). Na realidade, a sua obra não deixa de ser obra de médico. Percebe-se o profissional em cada página, na sua experiência de apreciação do ser humano, na sua capacidade de fixar os traços fisionômicos, as linhas e as formas do corpo dos personagens retratados.

Na sequência, reforça o seu grande conhecimento de produções de artistas famosos e a sua vocação de representar pessoas reais atreladas a pinturas ou gravuras expostas em museus famosos, com o intuito de ressaltar determinadas características que precisava destacar. Do repertório infinito que tinha à disposição, vai pinçando um olhar, uma figura excêntrica, um comportamento delicado, uma beleza sutil, uma altivez nas maneiras:

Mais telas, como o desenrolar das salas do Museu do Prado. Na casa da família Pimentel, Federico de Madrazo deixara os olhos de abismo da Marquesa de Montelo. Velázquez esquecera na calçada o seu Esopo: era a Chichica. E Pedro Paulo Rubens andara no bairro dos Funcionários, fundindo as cores radiosas de Maria de Médici às linhas das Leal exímias: a donairosa Carmelita, a Carmem majestosa e a divina Cocota (Nava, 1986, p. 149).

Para dirigir o leitor que porventura queira conhecer as produções referidas, em muitas ocasiões o autor fiz questão de citar os museus onde estão expostas as obras-primas citadas, a fim de garantir a veracidade de suas descrições. Na passagem acima, além de exaltar a profundidade do olhar da bela Marquesa de Montelo, de Federico Madrazo, o Esopo, de Diego Velásquez, perdido por seu turno na calçada, reencarna a personagem Dona Francisca de Oliveira, a Chichica, pessoa desprovida de qualquer atrativo, trajando-se sempre de cores lúgubres como o roxo e o preto e, além disso: «Não se maquilava, antes caiava-se como um pierrô e empapava os cabelos de negrita» (Nava, 1979, p. 50). Percebe-se, através dos adjetivos selecionados, o contraste entre a aparência de Chichica e a formosura das moças da família Leal.

Ao acompanhar os diversos estágios que resultaram na descrição acima, pode-se perceber a preocupação do autor em dirigir a atenção do leitor para a sua proposta, ou seja, sugerir um passeio por um museu imaginário cujas figuras retratadas se associam aos moradores da Belo Horizonte dos anos 1920. Ao utilizar a metáfora olhos de abismo para realçar a profundidade do olhar, o autor ativa a percepção do leitor, levando-o a estabelecer relações que não teriam sido alcançadas se a qualidade do olhar tivesse sido descrita de forma literal, pois a mesma se baseia na capacidade intuitiva e não num processo de raciocínio lógico. Importante salientar que ao se deparar com tantas fontes reveladoras da plasticidade do raciocínio de Nava, o leitor parece ser instado a buscar tais referências em livros ou outros suportes para colocá-los em confronto com as imagens geradoras do texto. 


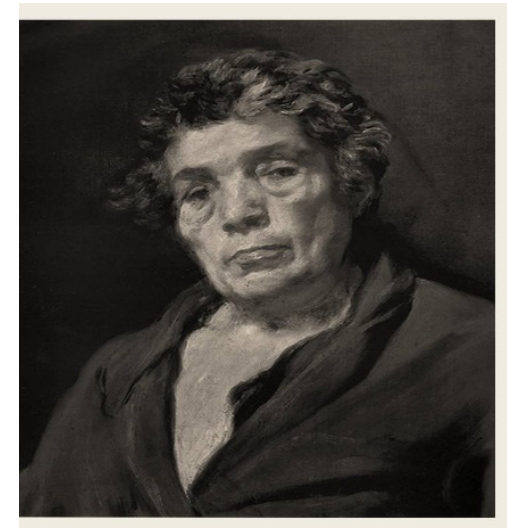

Figura 2. Reprodução do quadro Esopo, de Diego Velásquez, arquivada por Pedro Nava. Fonte: AMLB.

Em seguida, a apropriação da obra de Peter Paul Rubens está vinculada à percepção da imagem e ao modo como Nava apreendeu a realidade para traduzi-la em signo. As impressões sensoriais vão sendo transformadas em imagens mentais e traduzidas para linguagem verbal, evocando as telas do pintor em sua valorização das cores e movimentos e no seu estilo dinâmico e emocional ao descrever a sensualidade e a delicadeza das moças pertencentes à família Leal. A pintura de Rubens apresenta ainda uma forma aberta em que a impressão de movimento é intensificada pelas linhas diagonais que extrapolam o limite do enquadramento, criando uma sensação de continuidade: «A linha diagonal (dinâmica) é dramática, por excelência, sendo uma das principais características de Rubens, que tornaram os seus quadros inconfundíveis» (D’Avila, 2012, p. 56). Resulta daí a analogia de Pedro Nava em relação à fusão das cores de Maria de Médici às linhas das Leal, moças tidas como perfeitas e que surpassavam as demais em virtude, elegância e galhardia: o requinte e a graça de Carmelita, a imponência e a nobreza de Carmem, somados à beleza e ao encanto de Cocota, características inerentes ao barroco de Rubens.

$\mathrm{Na}$ passagem a seguir, somente o olhar especializado de um médico seria capaz de captar as diferentes características anatômicas que caracterizavam os seus colegas de classe:

Éramos de toda qualidade. Obesos e magros, atletas como o Marcelo Miranda Ribeiro, hércules como o Xico Coelho Lisboa, escanifrados astênicos como o Cagada, pernaltas, borra-baixinhos, joelhos varos e valgos, pés chatos como os de Baco de Miguelângelo ou arqueados como os do Édipo de Ingres, todas as anatomias ali se confundiam: desde as mais raras onde se podia vislumbrar ora o braço desfechante de Apolo do Belvedere, ora o esterno-cleido do Davi da Academia, a panturrilha do Discóbolo de Miron, os maléolos do Aurige de Delfos - até às mais numerosas frolando o disforme, os aplásicos, os grotescos e os quase patológicos que Charcot e Richer foram buscar, também, nas galerias dos museus (Nava, 1976, p. 65).

Baseado na observação do médico e na experiência clínica de sua especialidade, a Reumatologia, o autor foi entrelaçando as diversas anatomias num cruzamento de características positivas e negativas, encanto e fealdade, refinamento e grotesco. Tais urdiduras ainda se beneficiam da condição de artista plástico do narrador e de sua extraordinária capacidade de apreender as linhas e as formas dos personagens, além de estabelecer mediações entre estes e as figuras de telas e esculturas de artistas renomados. 
A arte transformada em palavras

Entre os alunos do Colégio Pedro II havia os gordos e os magros, mas também havia aqueles que se destacavam pelo físico avantajado e comparável a um atleta ou a um herói grego. A apurada percepção do autor de associar características psicológicas ao aspecto físico leva-o também a diagnosticar entre os colegas raquíticos, quase descarnados, aqueles que apresentavam estados depressivos, ou seja, os escanifrados astênicos. Havia ainda os que se identificavam pelas longas pernas ou, ao contrário, pelas ditas excessivamente curtas — os borra-baixinhos, gíria empregada no Pedro II para nomear os últimos - Alguns eram identificados, especialmente nas atividades esportivas, pelos joelhos distantes e pelas pernas arqueadas como as de um cowboy (os de joelhos varos) ou, ao contrário, pelos joelhos voltados para dentro, encostando um no outro e prejudicando a marcha natural (os de joelhos valgos).

As aproximações entre a galeria de retratos dos colegas e esculturas famosas podem ser encontradas na passagem em que o verbal se deixa contaminar pelo icônico na busca da representação ou reprodução fidedigna. Alguns colegas tinham pés chatos como os de Baco. Esta escultura, esculpida por Michelangelo, está exposta no Museu Nacional de Bargello, em Florença, Itália, e apresenta o deus da mitologia romana numa posição que o representa com o pé esquerdo plantado no chão, evidenciando a ausência de curvatura de seu arco interno. Outros ostentavam pés arqueados como os de Édipo. A pintura referenciada, denominada Édipo e a Esfinge, do artista francês Jean-Auguste-Dominique Ingres, e que se encontra no Museu do Louvre, em Paris, retrata o personagem de perfil e a angulação do quadro deixa ver, com clareza, o acentuado arqueamento interno do pé.

Aproximações anatômicas nobres e raras também são registradas pelo autor. Uma delas se volta para o braço desfechante de Apolo de Belvedere, escultura do deus grego que faz parte do acervo do Museu Pio-Clementino, um dos museus do Vaticano. Quando encontrada, a estátua estava alijada dos dois braços. Como traz em suas costas um arcaz de flechas, supõe-se que Apolo estivesse em ato de atirar uma flecha, cujo arco estaria em sua mão esquerda, daí a cuidadosa observação de Pedro Nava sobre a anatomia e a forma artística de um braço em posição de disparo. Já um pescoço hirto e alinhado também marcava presença entre os alunos do colégio. $\mathrm{O}$ esterno-cleido, músculo largo e robusto da face lateral do pescoço e amplamente visível na escultura de Davi, de Michelangelo, assinala a postura arrojada do herói bíblico do qual se aproximavam, em seu realismo anatômico, alguns dos personagens rememorados pelo memorialista. Importante observar o cuidado com que Pedro Nava indica a qual Davi ele se refere, pois sinaliza que se trata «do Davi da Academia», ou seja, o original que está na Academia de Belas Artes de Florença, uma das esculturas mais famosas do artista renascentista.

Já a proeminência muscular da parte posterior da perna, a popular barriga da perna remete a Discóbolo, do escultor grego Míron, escultura que representa um atleta momentos antes de lançar um disco, provavelmente a estátua de desportista em ação mais famosa do mundo, concebida possivelmente para homenagear um atleta vitorioso no antigo pentatlo. Ao se observar a escultura pode-se verificar, com nitidez, os músculos da panturrilha agindo na postura e equilíbrio do corpo, detalhes que merecem a observação de Pedro Nava nas suas caracterizações. Já a referência à estátua Auriga de Delfos tem por objetivo chamar a atenção para os maléolos, ou seja, as saliências ósseas do tornozelo, muito evidentes na referida escultura que retrata um condutor de quadriga, 
um carro semelhante a uma biga, conduzido por quatro cavalos, lado a lado, utilizado nos jogos olímpicos antigos e em outros jogos. A quadriga foi adotada na Roma antiga nas corridas de carruagens, tendo sido o Coliseu palco de muitas delas, exibidas em inúmeros filmes épicos. A referida estátua faz parte do acervo do Museu Arqueológico de Delfos.

Em contrapartida, Pedro Nava também registrou as anatomias mais numerosas e menos nobres que faziam parte de seu grupo de colegas e que incluíam tipos caricatos, bizarros e em desvantagem na aparência e na essência. Para validar esse registro, invoca como argumento de autoridade os médicos Charcot e Richer. Jean-Martin Charcot foi um estudioso da degeneração das articulações encarregadas de carregar o peso do corpo, como os pés e as pernas. Foi o responsável pela descrição da «junta de Charcot», uma deformação óssea que ocorre devido à falta de sensibilidade. Também alcançou fama no terreno da Psiquiatria e da Neurologia, na segunda metade do século XIX. Sua atuação fundamenta-se na clínica do visível que Foucault (2008) identifica como a clínica da observação. Entretanto, Paul Marie Louis Richer foi discípulo de Charcot. Era médico, mas dominava a anatomia artística, o desenho e a modelagem. Usava a sua capacidade para ilustrar partes do corpo humano e reproduzia as crises histéricas de pacientes de Charcot a ponto de o mestre afirmar que as doenças descritas poderiam ser facilmente diagnosticadas pelos desenhos perfeitos de Richer (Maranhão, 2017). Richer também contribuiu com a medicina de sua época criando uma coleção de estátuas destinadas ao ensino da Neurologia. Compreende-se, desse modo, o fato de Pedro Nava ter trazido em seu apoio o nome de ambos, pois Charcot e Richer «sempre foram vivamente interessados em documentar imagens das doenças como forma de arte» (Maranhão, 2013, p. 81).

Os adjetivos abundantes empregados nas caracterizações extrapolam a mera função de informar, pois há uma intenção estético-expressiva que estabelece princípios capazes de explicar as escolhas no sentido de caracterizar os colegas, uma vez que todas as anatomias ali se confundiam. Os adjetivos correspondem, aqui, ao desejo do autor de mostrar as diferentes características dos colegas com quem conviveu e que deixaram profundas marcas em sua vida e em sua memória.

\section{A composição dos personagens através do desenho}

É notável a preocupação de Pedro Nava ao retratar os seus personagens. À maneira do médico, ele os dissecava meticulosamente, não perdendo nenhum detalhe, o que comprova o seu espírito observador. Dessa forma, sua prosa é marcada por uma profusão de imagens, tons e formas. O gosto pelo plástico explica um de seus métodos de trabalho - o desenho como anotação - ponto de partida para a descrição com palavras. Esse espírito visual tem, no entanto, implicações muito mais amplas na medida em que acaba dando ao autor uma imagem plástica das pessoas que vê e das cenas que vive, de tal sorte que lhe possibilite oferecer ao leitor uma descrição vívida e colorida dos tipos e dos acontecimentos. Um dos pontos altos de sua prosa é, com efeito, essa capacidade imagética, de desenhista, que em dois ou três traços apresenta tipos e ambientes com forte densidade.

Um grande montante de textos descritivos do memorialista está vinculado a desenhos do autor ou baseado em 
A arte transformada em palavras

figuras arquivadas com o intuito de utilização futura. Trata-se de uma atitude de recuperação: trazer de volta um conjunto de imagens significa produzir uma conjugação entre linguagem e pensamento. É, portanto, prioritária a relação estabelecida entre imagem e pensamento, a maneira como os elementos estão interligados e a maneira como são transformados. O que se pretende com este estudo é demonstrar que o lidar com a matéria-prima da criação está diretamente relacionado a técnicas. Se sabe que a busca do escritor se apoia no espaço pessoal que encontra para lidar com essa dificuldade. Os recursos criativos surgem como os modos de lidar com as propriedades dessas matérias-primas, ou seja, modos de transformação. Há uma potencialidade de exploração dada por elas e é isso que se almeja demonstrar, agora via mapeamento, tendo como modelo o processo de escritura de Pedro Nava, pois toda a documentação armazenada pelo autor mostra um ambiente propício para se pensar a relação entre a palavra e a imagem. As linguagens verbal e visual desempenham funções com diferenças bastante definidas, no entanto, não se apresentam de forma estanque, mas se inter-relacionam de modos diversos. Nesse sentido, o desenho guarda conexões sob a forma de organização de ideias.

As descrições feitas por Pedro Nava, muitas vezes eram vinculadas a desenhos elaborados para tal. No caso da descrição de pessoas, o recurso utilizado era a caricatura ou a fotografia. Ao relembrar o professor de Clínica Cirúrgica, Borges da Costa, fiz um levantamento dos traços do mestre e anota tais dados, como uma possibilidade de uso, numa ficha que recebeu o número 8 e se refere ao ano de 1926. A figura desenhada ia então recebendo anotações. No conjunto, essas informações eram valiosas para os procedimentos descritivos indispensáveis ao texto que o autor tinha em mente sobre o personagem, havendo a «concretização do desenvolvimento de um pensamento marcadamente visual» (Salles, 2006, p. 110). A fim de se ter ideia do apoio oferecido pela caricatura para a descrição de características físicas, observe-se o trecho aqui reproduzido:

E como era? o jeitão do Borges. Cabeça grande, herdada com certeza do ramo nortista. Pescoço curto e forte, um pouco metido para dentro dos ombros largos e um quanto levantados. Tórax possante. Corpulento sem ser barrigudo. Mãos de cirurgião - hábeis, expressivas, acompanhando como belo elemento mímico tudo o que dizia. Era pouco corado, pele muito clara. Nariz agudo e breve semelhante a um rostro de ave. Olhos enormes, arregalados, levemente estriados pequenas veiazinhas nas escleróticas, pupila penetrante castanho-escuro. Sua expressão alternava o pensativo com o alegre. Sua boca era bem-feita, dentes conservados, várias vezes à mostra no riso fácil. Usava bigode curto, o redondo do rosto terminando por queixo firme, recolhido e calcando o pescoço, fazendo aparecer seu esboçado double-menton. A voz era agradável. Falava geralmente um pouco devagar e na altura em que falam as pessoas bem-educadas. Mesmo irritado, não elevava seu timbre. [...] essa voz que estamos descrevendo só subia e ficava mais aguda quando no desfecho de caso pitoresco que contava ou quando Borges soltava uma daquelas risadas que faziam-no até lacrimejar, chorar de gargalhar. Lembro de uma destas explosões de chiste no exame final do nosso Cisalpino. O moço diamantinense estava afobado e quando Borges perguntou, a propósito do caso da prática qual? a operação indicada, o aluno em vez de dizer - gastro-entero-anastomosetransmesocólica - soltou - gastro-entero- anastomose-transiberiana posterior de Bilroth. O examinador estourou, riu de morrer e acabou mandando o Cisalpino com seu dez... (Nava, 1979, p. 249). 


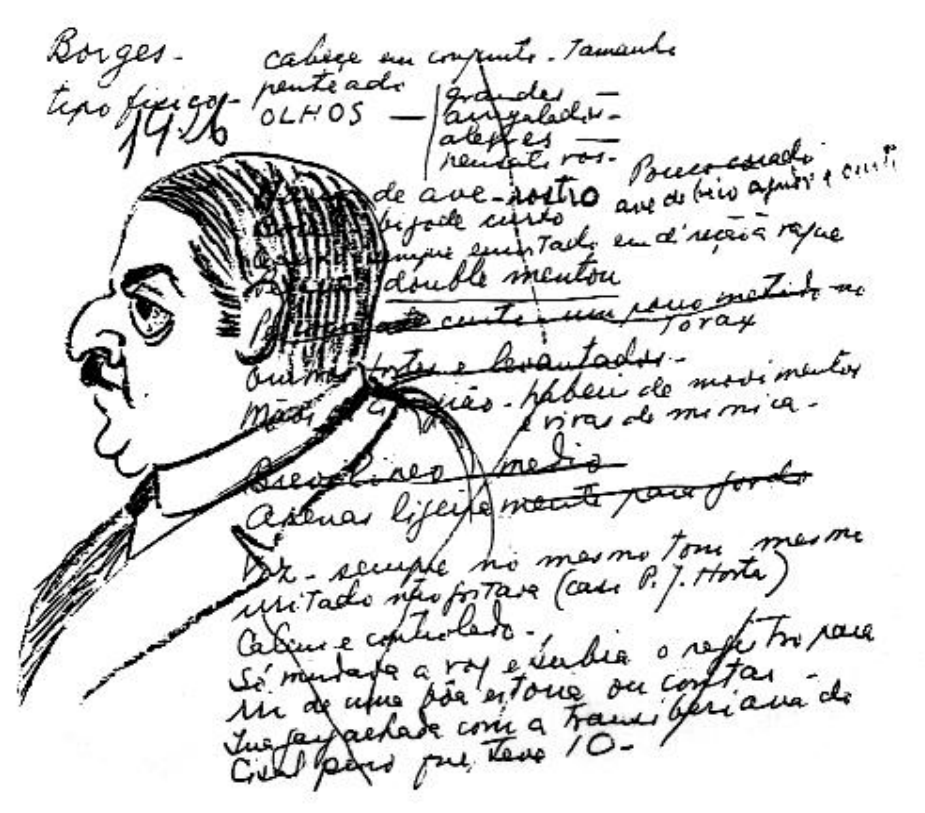

Figura 3. Caricatura de Borges da Costa esboçada por Pedro Nava. Fonte: AMLB.

Uma caricatura proporciona grande riqueza de recurso informacional. Nava fiz consultas, organizou arquivos, compôs fichas. Acentua-se a relevância da atitude de recuperar e armazenar para organizar um extrato de ideias e informações, para com ele expressar um conteúdo de real significação. Na ficha organizada pelo autor e que trazia os dados sobre Borges da Costa aparecem vários detalhes relevantes para a recuperação de sua imagem: tipo físico — cabeça em conjunto — tamanho, penteado - ; adjetivação para caracterizar os olhos do mestre (grandes, arregalados, alegres, pensativos), pouco corado; nariz de ave, rostro (ave de bico agudo e curvo); pescoço doublementon, pescoço curto, um pouco metido no tórax; ombros fortes e levantados; mãos de cirurgião, hábeis de movimento e vivas de mímica; brevilíneo médio; apenas ligeiramente para gordo; voz, sempre no mesmo tom, mesmo irritado não gritava (caso P. J. Horta); calmo e controlado, só mudava a voz e subia o registro para rir de uma boa estória ou contar; sua gargalhada com a transiberiana do Cisalpino que teve 10 .

A atitude de estar aberto a captar imagens e impressões estende-se, como se pode perceber, a tudo que parece semelhante (princípio da similaridade). A aproximação de Borges da Costa a um rostro de ave representa uma riqueza que se perde quando não se conhecem as informações embutidas nas correlações que produz. Já os adjetivos abundantes empregados na sua tipificação têm por objetivo fixar não apenas os atributos físicos do ilustre professor, mas também as suas características psicológicas, como observa Lapa (1998, p. 119): «O bom escritor revela-se num grande número de qualidades, mas entre elas sobressai a de aplicar com precisão e pitoresco os seus adjetivos». A utilização da forma verbal estourou [de rir], cuja massa sonora é adequada ao conteúdo significativo, é relevante no contexto em questão, pois o professor era dado ao chiste, diferenciando-se dos demais, sempre muito circunspectos.

Os professores de Pedro Nava, tanto os do tempo colegial quanto os mestres da Faculdade de Medicina foram 
homenageados em suas reminiscências de forma carinhosa e se somam à enorme galeria de personagens e tipos humanos que desfilam por todos os volumes das memórias do autor. Alguns deles mereceram, além de descrição minuciosa, a elaboração de desenhos e caricaturas que garantiram ao memorialista a recuperação de detalhes primorosos para retratá-los com a maior fidedignidade, embora não dispusesse, em muitos casos, de nenhuma fotografia na qual embasar-se. O professor de Latim, Eduardo Gê Badaró, foi mais um dos mestres homenageados:

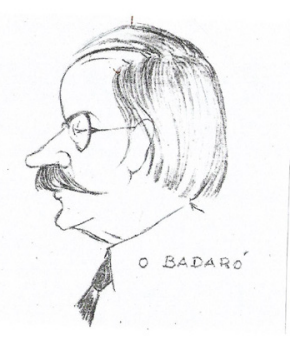

Figura 4. Caricatura do Professor Doutor Eduardo Gê Badaró. Fonte: AMLB.

Tratava-se de um homem de conspícua cabeleira, bigodes pretos grisalhando, moreno claro, muito míope, alto de estatura, cheio de tronco, muito fino de pernas e dotado duns pés-de-anjo que podiam rivalizar com os de Álvaro Maia. Vestia-se dumas alpacas acinzentadas com que usava invariavelmente um colete transpassado de linho branco. Seus colarinhos e punhos eram esmaltados, suas gravatas suntuosas. Calçava sempre botina de amarrar, pelica amarela ou pelica preta. Quando se lhe entreabria o paletó, vislumbrava-se na sua cinta a garrucha de que ele não se apartava. Que haveria? na sua vida, exigindo esse estado de defesa permanente? (Nava, 1976, p. 14).

O desenho como processo figurativo depende de uma série de fatores que têm no artista na sua chance de expressão. Dentre estes fatores estão as peculiaridades características da figura que se pretende desnudar, para o que a adjetivação desempenha um papel primordial. Pedro Nava utilizou o desenho de memória, ou seja, o desenho produzido utilizando as imagens que estão guardadas na mente. Estas, aliadas à criatividade do autor, produzem a somatória da expressão, realização e construção final da figura que se pretende apresentar ao leitor. A caricatura contribui para atualizar os dados que estavam internalizados e trazem à tona alguns detalhes importantes como, no caso do professor em questão, a sua acentuada miopia e os pés muito grandes, atenuados pelo eufemismo pé de anjo.

O professor de Latim é retratado não apenas na aparência física, mas também na sua forma de se vestir, revelando um homem elegante no trajar e justificando a sua ascendência ilustre. Nas primeiras décadas do século $\mathrm{xx}$, os homens utilizavam peças de alfaiataria e a vestimenta do dia a dia era o terno (camisa, paletó e colete). Durante o dia usavam cores claras e, à noite, escuras. As camisas não tinham golas e punhos fixos. Elas eram removíveis e poderiam ter as cores trocadas, a depender da ocasião (Oliveira, 2014). Um outro detalhe anotado 
por Pedro Nava era o hábito de uma sociedade com capacidade para obter e empregar armas, independentemente das instâncias governamentais, pois andar armado era comum naquele início de século.

A descrição física minuciosa e exigente é um desnudamento ontológico. Sobre a imagem quase apagada pelo tempo, o autor aplica novos reagentes que lhe permitem restaurar o perfil dos dois professores em sua nitidez primitiva. A aptidão de Pedro Nava para as artes plásticas reflete-se em seu texto. O gosto pelo plástico explica um de seus métodos de trabalho - o desenho como anotação - como um ponto de partida para a descrição com palavras. Ao utilizar o desenho para recuperar o passado, Nava construiu uma memória material, pois a reprodução desenhada é mais objetiva e permite que o autor não fosse traído pelas inconstâncias da memória individual. $O$ processo de criação se embasa nas anotações que se cruzam na narrativa, construindo um universo particular de retomada da realidade. A pontuação deslocada, uma inovação estilística do autor, tem por objetivo marcar o ponto exato onde se dá a interrogação ou a exclamação, resultando numa narrativa que se aproxima da linguagem oral.

\section{A composição dos personagens através da literatura}

Ao descrever os seus personagens, Pedro Nava também os associou a protagonistas da literatura, como deixa entrever na seguinte passagem:

É assim que não posso reler Crime e Castigo sem dar a Raskolnikov a aparência do meu colega, o radiologista João Fortes ou a do meu primo João Batista dos Mares Guia; Os Maias, sem envultar Carlos Eduardo (apesar de seus cabelos e barbas pretas) em Rafael de Paula Sousa; O Crime do Padre Amaro e a Relíquia sem pôr a São Joaneira na Dona Bráulia da Pensão Muriti, a Ameliazinha na Nair Cardoso Sales Rodrigues e a titi Patrocínio (que pecado!) na minha santa tia Marout. E assim faço com os vultos de Balzac, Anatole, Proust. Maria do Carmo é a Duquesa de Guermantes (Nava, 1979, pp. 201-202).

Ao descrever o dormitório da Quarta Divisão do internato e os colegas com quem dividia o imenso espaço cujo cheiro fétido o acompanhou para sempre, o memorialista apropria-se de forma voluntária de uma passagem do romance $O$ Ateneu, de Raul Pompéia, livro que exerceu uma marcante influência no seu relato dos tempos como estudante no Colégio Pedro II, ratificando a presença e a importância da literatura em seu processo de criação:

Os colegas começavam a dormir. Alguns afetavam um esboço comovedor de sorriso ao lábio; alguns a expressão desanimada dos falecidos, boca entreaberta, pálpebras entrecerradas, mostrando dentro a ternura embaciada da morte [grifos do autor]. Mas ...com todos os diabos! Isto é Ateneu, não é meu, é Chácara do Mata e nós estamos em meio século dos depois ou mais, estamos no Campo de São Cristóvão ... (Nava, 1986, p. 360).

Uma figura feminina marcante nas memórias de Pedro Nava é associada a personagens da literatura que tiveram suas vidas interrompidas precocemente, em virtude da aparência frágil e sem vigor da jovem retratada. A adjetivação múltipla realça a extrema magreza da personagem e a sua aparência esquálida é reiterada pela expressão metafórica toda ossos. Já a repetição da conjunção e sugere a insistência e a intensificação do estado de prostração em que a mesma vivia: 


\section{A arte transformada em palavras}

A outra tão aérea e pálida, que eu gostava de acompanhar e olhar no bonde, era lenta e langue e magra como se fosse morrer a cada instante. Toda ossos e cabelos louros ela deslizava como as heroínas dos romances em que as moças tísicas são amadas desesperadamente. Constança, Ismália - ela era a «morta virgem», a «pálida e loura, muito loura e fria», ou aquela que «quando morreu choravam tanto, chovia tanto naquela madrugada ...» Eu a amei num setembro, tempo da fumaça e ela sugeria coisas aéreas, aragens frias, nuvens de incenso, longos lírios, perfume funeral de violetas (Nava, 1979, p. 273).

Constança, a primeira personagem referida por Pedro Nava, era prima e noiva do poeta Alphonsus de Guimaraens e morreu quando o poeta tinha apenas dezoito anos. Marcado pela morte da eleita, sua poesia é quase toda caracterizada pelo tema da morte da mulher amada. Já Ismália, do poema do mesmo autor escrito em 1960, enlouqueceu e se suicidou em seu desvario, saltando de uma torre. A «morta virgem» é Elzira, do livro de Pedro Ribeiro Vianna (1883), a moça tísica que morre nos braços do amado, impedida pelos pais de desposá-lo. A «pálida e loura, muito loura e fria» é a personagem defunta do poema de António Feijó (2004). Aquela que «quando morreu choravam tanto, chovia tanto naquela madrugada ...» é Estela, do poema Lágrimas de Cera, de Raul Machado (1924). Assim, em seus livros, Nava captou os personagens em suas características individuais, idiossincrasias apreendidas em sua complexidade, e é por isso que tais figuras ganham tanta força quando se manifesta a emoção provocada pelo fato narrado.

Descrições pondo em confronto o velho e o novo, assim como o belo e o feio, são facilmente encontradas no percurso criativo de Pedro Nava. Na passagem abaixo, fica evidente tal contraste entre a beleza da esposa e a aparência hedionda do marido, que é comparado ao personagem central do livro de Victor Hugo, o corcunda de Notre-Dame. Para salientar a formosura da personagem, o autor vai buscar nas produções literárias os atributos que julgava mais adequados para compor a figura em questão:

Nunca me esqueci da noite em que acompanhei tio Salles a uma casa perto do Anglo, onde ele foi visitar homem de feia catadura, casado com uma linda moça. Era o poeta Antônio Francisco Da Costa e Silva, cuja cara amarela parecia um bolo de miolo de pão com os furos dos olhos, das ventas e da boca. Estava recém-casado com a bela Alice Salomon, a dos cabelos mais negros que a asa da graúna, das pupilas noturnas, do rosto oval, da pele de leite, do pescoço de cisne e do colo-de-alabastro-que-sustinha. Linda, assim, mesmo linda, não via o Quasímodo e apaixonara-se pelo talento e pelo estro do vate simbolista (Nava, 1986, p. 218).

À lembrança resgatada pela memória, somam-se as imagens selecionadas numa composição poético-anatômica de elementos recortados e implantados na construção da personagem. Em José de Alencar (2012) Pedro Nava foi buscar os cabelos negros de Iracema; os olhos escuros foram encontrados no poema Rosário, de Vinícius de Moraes (2000), enquanto o rosto oval foi captado da poesia Nua, de Saúl Dias, pseudônimo de Júlio Maria dos Reis Pereira (1980). A pele de leite, retirada do conto «O relógio», de autoria de Mário de Andrade (1930), escrito sob o pseudônimo de Luiz Antônio Marques, teve por objetivo chamar a atenção para a brancura da pele de Alice, característica muito comum entre as mulheres no início do século xx. Já o pescoço de cisne o autor foi encontrar na poesia Resíduo, de autoria de Carlos Drummond de Andrade (2012), e o colo de alabastro foi pinçado de $O s$ Lusíadas, Canto III, de Luiz de Camões (2014).

A literatura, assim, fornece os modelos para que o autor possa compor um conjunto de beleza só possível de ser alcançado pela soma de partes de corpos diferentes de figuras femininas, o que lhe rendeu a fama de desenvolver 
uma «escrita frankenstein»: «Por meio da reunião de caracteres de várias pessoas numa só personagem, Nava cria personagens frankensteins, fundadas na verossimilhança e na invenção» (Garcia, 1997, p. 32). Importante ressaltar que nem sempre o autor colocou em destaque, no texto, as apropriações que faz de elementos da literatura, deixando apenas uma pista como, no exemplo acima, quando inicia a descrição com uma citação célebre «cabelos mais negros que a asa da graúna», de José de Alencar, o que leva o leitor a supor — e a constatar, se for buscar as demais referências - que as características elencadas também foram colhidas em outros autores.

Em alguns momentos, Pedro Nava lançou mão de mais de um recurso para acentuar os traços de determinado personagem misturando os artifícios imagéticos e provocando, no leitor, a curiosidade de buscar as fontes no intento de concretizar as palavras em imagens. Para recuperar, de forma precisa, a figura de João Alphonsus, Nava superpus a foto do avô do escritor e a imagem de um ator de cinema, toma emprestado os retratos de Velázquez, e complementa os dados com uma foto que recebeu do amigo, em seus tempos de Belo Horizonte:

João Alphonsus à época de $A$ Revista tinha vinte e quatro anos completos. Era um moço de pouca altura, brevilíneo, mais para gordo. Quem conhece as obras completas de seu pai publicadas por Alphonsus de Guimaraens Filho pode ter uma idéia de como ele era de corpo - olhando a fotografia de seu avô Albino da Costa Guimarães. De cara ele se parecia muito com aquele Hank Mann que foi um dos boxeurs de Carlito em Luzes da Cidade ou fazendo comparação mais nobre, com o Conde-Duque de Olivares nos retratos pintados por Velázquez. Estou aqui a vê-lo numa foto que ele me ofereceu (Nava, 1979, p. 217).

Importante salientar que as imagens selecionadas para a caracterização do poeta confirmam, de forma peremptória, a sua aparência: «A testa ampla começando a ser aumentada pela calvície precoce. As sobrancelhas afastadas e levantadas no centro dando-lhe expressão triste e embaixo dela os olhos pequenos, espertos, muito escuros. Tinha a boca apertada e o queixo obstinado» (Nava, 1979, p. 217).

Ao pintar com palavras, Pedro Nava cria no leitor a ilusão de ser um espectador que assiste a um espetáculo cuja narrativa está lendo. A imagem pictórica age, assim, como substituta de uma ausência que só pode apresentarse na forma de uma representação, pois os signos visuais que tal representação utiliza pertencem, na verdade, à linguagem da criação. A ideia da representação pressupõe uma afinidade cujos efeitos abarcam tanto o domínio da linguagem quanto o da imagem, de tal forma que as palavras passam a ser julgadas segundo os critérios da pintura, da fotografia, da caricatura, ou seja, o que o autor descreve transforma-se em imagem na mente de quem lê.

\section{Conclusão}

Ao focalizar a tradução intersemiótica que se realiza na criação e o modo como as telas, as esculturas e as caricaturas vão sendo incorporadas à obra, Pedro Nava assimilou essa visualidade e a transformou em prosa poética, justapondo a sua escrita e as imagens mencionadas numa recriação da realidade. Percebe-se, assim, a plasticidade do raciocínio do autor que distingue, perfeitamente, a mensagem estética da mensagem puramente informativa, percepção alcançada pela força da mente criadora. Indagado sobre a importância de se recorrer ao desenho em sua escritura, o autor assim se posicionou: 
De fato. O desenho é muito interessante porque ele traz consigo uma carga muito grande de associação de ideias, é um instrumento de lembranças. Se eu tenho que reconstituir, por exemplo, uma toilette de minha mãe, essa toilette me vem com todos os elementos e eu faço um desenho de como era a roupa (Nava, como se citou em Panichi, 2016, p. 200).

Ao ser questionado sobre o porquê, então, não ilustrar os livros, Pedro Nava foi contundente:

Muitas pessoas me falaram sobre isso. Na realidade, tenho uma documentação muito grande com fotografias de minha família que me foram enviadas principalmente após a publicação dos livros. Eu já tenho arquivadas cerca de mil fotografias e faltam ainda cerca de trezentas para completar o arquivo, que é o arquivo de minha série de memórias. Mas fiz a opção de não ilustrar os livros com este material porque entendo que a ilustração limita a interpretação do leitor e, às vezes, traz algumas desilusões. O personagem, às vezes, tem uma certa beleza, mas aí a gente publica a foto de um sujeito feio, com um bigodão, aquela coisa toda... E o personagem não merece a cara daquele cabra. Mas, ainda assim, tenho um projeto para a publicação posterior das fotos de todos os meus personagens. As ilustrações, como documento à parte, devem ser publicadas e é por isso que estou fazendo este arquivo (Nava, como se citou em Panichi, 2016, p. 201).

Ao recompor o passado e reproduzir a sociedade, hábitos e costumes da sua época, as memórias de Pedro Nava ultrapassam os limites da autobiografia individual. Assim, as memórias não passam só pela autoria, por aquele que lembra, mas pelo narrador que traz para o texto a somatória de experiências de linguagem e estas experiências são sempre enriquecidas pela tendência plástica de seu raciocínio. Em seus escritos o autor é um controlador da estruturação dos fatos, mas é muito mais um manipulador da função estética, dramática e lírica de todas as suas lembranças.

A par da memória individual, Pedro Nava construiu uma memória material baseada em seus arquivos de criação. As imagens geradoras de suas descrições partem de suas lembranças, de suas vivências e recordações afetivas. Os desenhos e gravuras arquivados pelo autor ampliam, assim, os territórios da memória para além de sua capacidade de armazenamento de lembranças e constituem parte fundamental do projeto de construção da obra. Com o apoio de arquivos e registros, anotações realizadas em diferentes ocasiões, a sensação de conteúdo difuso se torna resolvida quando o autor empreende a tarefa de construir o texto. Ao preservar os arquivos com os quais organizou o conteúdo de suas memórias, Pedro Nava possibilitou o desvendamento do seu processo de criação e de sua forma de perceber a realidade. 


\section{Referências bibliográficas}

1. Andrade, C. D. de. (2012). A rosa do povo. São Paulo: Companhia das Letras.

2. Andrade, M. de. (1930, março 29). O conto semanal. Jornal Diário Nacional. São Paulo.

3. Andrade, M. de. (1982). Correspondente contumaz: cartas a Pedro Nava. (Ed. prep. por F. R. Peres). Rio de Janeiro: Nova Fronteira.

4. Alencar, J. de. (2012). Iracema. Cotia: Ateliê Editorial.

5. Bandeira, M. (1946). Antologia de poetas brasileiros contemporâneos. Rio de Janeiro: Zélio Valverde.

6. Camões, L. V. de. (2014). Os Lusíadas. São Paulo: Melhoramentos.

7. Cressot, M. (1980). O estilo e as suas técnicas. (Trad. M.C. Ferreira). Lisboa: Edições 70.

8. D’Avila, P. A. (2012) Análise dos princípios do processo de design da pintura de Peter Paul Rubens: o caso da obra «O rapto das filhas de Leucipo» (Dissertação de mestrado). Centro Universitário Ritter dos Reis, Porto Alegre, RS, Brasil.

9. Dias, S. (1980). Obra poética. Porto: Brasília Editora.

10. Feijó, A. (2004). Líricas e bucólicas. Porto: Magalhães, 1884. In Mouzinho, A. R. (Org.). A circulatura do quadrado: alguns dos mais belos sonetos de poetas cuja mátria é a língua portuguesa (p. 165). Porto: Edições Unicepe - Cooperativa Livreira de Estudantes do Porto.

11. Foucault, M. (2008.) O nascimento da clínica. São Paulo: Forense Universitária.

12. Garcia, C. F. (1997). A escrita frankenstein de Pedro Nava. Fortaleza: EUFC.

13. Grésillon, A. (2007). Elementos de crítica genética: ler os manuscritos modernos. (Trad. C. C. Velho et al.). Porto Alegre: Editora da UFRS.

14. Guimaraens, A. de. (1960). Obra completa. Rio de Janeiro: J. Aguilar.

15. Hay, L. (2007). A literatura dos escritores: questões de crítica genética (Trad. C. P. B. Mourão). Belo Horizonte: Editora UFMG.

16. Lapa, M. R. (1998). Estilística da língua portuguesa (4a edição). São Paulo: Martins Fontes.

17. Machado, R. (1924). Asas aflitas. Rio de Janeiro: Imprensa Oficial.

18. Maranhão, P. F. (2017). A arte e a neurologia de Paul Richer. Arquivos de Neuro- Psiquiatria, 75(7), 484-487. http://www.scielo.br/scielo.php?script=sci_arttext\&pid=S0004-282x2017000700484\&Ing=en\&nrm=iso doi. org/10.1590/0004-282x20170067

19. Maranhão, P. F. (2013). Henri Meige: a síndrome, o artista e o martelo. Revista Brasileira de Neurologia, 49(2), 80-81.

20. Martins, N. S. (2012). Introdução à estilística: a expressividade na língua portuguesa (4a edição). São Paulo: Editora da Universidade de São Paulo.

21. Nava, P. (1983). Baú de ossos: memórias 1 (6a edição). Rio de Janeiro: Nova Fronteira.

22. Nava, P. (1986). Balão cativo: memórias 2 (4a edição). Rio de Janeiro: Nova Fronteira. 
A arte transformada em palavras

23. Nava, P. (1976). Chão de ferro: memórias 3. Rio de Janeiro: José Olympio.

24. Nava, P. (1979). Beira-mar: memórias 4 (2a edição). Rio de Janeiro: José Olympio.

25. Panichi, E. (2016). Processos de construção de formas na criação: o projeto poético de Pedro Nava. Londrina: Eduel.

26. Moraes, V. de. (2000). Antologia poética. Rio de Janeiro: Companhia do Bolso.

27. Oliveira, J. M. (2014). A história da moda masculina: década de 1910. https://mondomoda.com.br/2014/05/19/ a-historia-da-moda-masculina-decada-de-1910/

28. Ostrower, F. (1999). Acasos e criação artística (2a edição). Rio de Janeiro: Elsevier.

29. Salles, C. A. (2006) Redes da criação: construção da obra de arte. São Paulo: Editora Horizonte.

30. Vianna, P. R. (1883). Elzira: a morta virgem. Rio de Janeiro: Livraria H. Antunes LTDA.

31. Willemart, P (2009). Os processos de criação na escritura, na arte e na psicanálise. São Paulo: Perspectiva. 